\title{
Well- Being: A Study of Smoker and Non-Smoker Adolescents
}

\author{
Mohd Amin Wani*, Prof. Mahmood S. Khan** \\ Research Scholar, Department of Psychology, Aligarh Muslim University, Aligarh
}

\begin{abstract}
Worldwide, tobacco use causes more than 5 million deaths per year, and current trends show that tobacco use will cause more than 8 million deaths annually by 2030 (WHO Report on the Global Tobacco Epidemic, 2011).Taking this into consideration an attempt has been made to study the Well-being among Frequent, casual and Non-Smoker Adolescents by comparing them with each other. The purposive sample for this study comprised of 150 Hostellers with equal number of Frequent, Casual and Non-Smokers from Aligarh Muslim University, Aligarh. The Scale of Well-being comprised of five dimensions viz: Physical, Mental, Social, Emotional and Spiritual developed by Jagsharanbir Singh and Dr. Asha Gupta, (2001) was used to gather information from the participants of this study. For the analysis of the data obtained, t-test was applied. A significant difference was found in Well-being among Frequent, Casual and Non-smokers when compared with each other: Non- smokers were found to show better well-being followed by Casual Smokers and least Wellbeing was found among frequent Smokers. The insignificant differences were found when Casual Smokers were compared with Non-Smokers on Mental dimension of Well-being and when Frequent Smokers were compared with Casual Smokers on Social dimension of Well-being. The frequency of smoking and its consequences are growing at an increased rate, viz-a-viz which needs to be controlled. Therefore an urgent intervention from the society in general and the Govt. and Non-govt. organizations in particular have to come forward in tackling spreading menace of Smoking among Adolescents.
\end{abstract}

Keywords: Well-being, Frequent Smokers, Casual Smoker, Non-Smokers and Adolescents.

\section{BACKGROUND OF THE STUDY}

Cigarette smoking is becoming increasingly widespread in developing as well as developed countries. In India Smoking has emerged as the third top risk for health loss. Smokers in India consumed an average of 8.2 cigarettes per day as tobacco claims a million lives every year in the country (**). Anyone who starts using tobacco can become addicted to nicotine. The younger a person is when they begin to smoke, the more likely they are to become addicted to nicotine/ nicotine dependent. Every Individual either Smoker or Non Smoker is very much aware about the harmful effects of smoking. Every pack of Cigarette has a statutory warning that "Cigarette Smoking is injurious to health" but still people smoke without bothering about their precious lives. If we simply ask people about the reasons of smoking, We could find so many answers like; they smoke to reduce a feeling of anxiety or nervousness, to calm down when upset or angry, to socialize with other smokers, to get relaxation when feeling restless, to satisfy an urge to smoke, when thinking about a different problem or when feeling depressed and so on. No matter what the reasons could be either Psychological, Social or political etc but the most important thing is the health or Well-being of an individual which is at the greater risk because of tobacco use. Every individual needs to quit smoke in order to be free from various kinds of diseases. Increased rate of industrialization in countries like India, smoking is the single most important risk factor for disease and the most common cause of early death (WHO, The world health report, 2002). The chronic diseases that are more common among smokers include myocardial infarction, stroke, arteriosclerosis, pneumonia, chronic bronchitis, and malignant Neoplasia of the lung, oral cavity, larynx, and digestive tract (IARC; 2004, USDHHS; 2004). Moreover, smoking weakens the body's self-defense mechanisms and elevates the risk of infectious disease. Regular passive smoking exposure is also associated with a considerable risk to health. The diseases and symptoms that arise largely correspond to those that are caused by active smoking (IARC; 2004, DKFZ; 2005). If we see in a real sense, Smoking has no single positive effect on the life of an individual. Every aspect of an Individual's life is negatively affected by tobacco consuming. Those people who have developed this habit or have become addicted must be addressed because smoking is a curse in the society, it needs to be eradicated. By consuming a Cigarette, a smoker is not only harming himself but the whole surrounding is affected by its harmful consequences. Keeping all the above things in consideration, It was decided to conduct a study on youths- Frequent, Casual and Non- Smokers by assessing their well-being.

\section{WELL-BEING}

Well-being is a positive outcome that is meaningful for people and for many sectors of society, because it tells us that people perceive that their lives are going well. Good living conditions (e.g., housing, employment)

DOI: $10.9790 / 0837-2109133140 \quad$ www.iosrjournals.org $31 \mid$ Page


are fundamental to well-being. Tracking these conditions is important for public policy. However, many indicators that measure living conditions fail to measure what people think and feel about their lives, such as the quality of their relationships, their positive emotions and resilience, the realization of their potential, or their overall satisfaction with life-i.e., their "well-being" (Diener \& Seligman 2004, Diener, 2009).

Well-being generally includes global judgments of life satisfaction and feelings ranging from depression to joy (Diener, et al 2009, Frey \& Stutzer, 2002). Well-being integrates mental health (mind) and physical health (body) resulting in more holistic approaches to disease prevention and health promotion (Dunn \& Beatty, 1973, Lyubomirsky, et al, 2005). Well-being is associated with numerous health-, job-, family-, and economicallyrelated benefits. For example, higher levels of well-being are associated with decreased risk of disease, illness, and injury; better immune functioning; speedier recovery; and increased longevity. Individuals with high levels of well-being are more productive at work and are more likely to contribute to their communities (Frey \& Stutzer, 2002; Tov \& Diener 2008).

There is no consensus around a single explanation of the concept of Well-being, but there is general agreement that at minimum, well-being includes the presence of positive emotions and moods (e.g., contentment, happiness), the absence of negative emotions (e.g., depression, anxiety), satisfaction with life, fulfillment and positive functioning (Frey \& Stutzer, 2002; Andrews \& Withey, 1976; Ryff \& Keyes, 1995).

When we talk about wellbeing, we are not only speaking of being joyful, although this is part of wellbeing. Dr. Martin Seligman, the "father" of positive psychology and a renowned researcher in both optimism and learned helplessness, describes five separate qualities (PERMA) to wellbeing i.e. i) Positive Emotion, ii) Engagement, iii) Relationships, iv) Meaning and v) Achievement. Each of these qualities can be independently developed and measured, and each may be valued differently by different individuals. Together, they constitute a set of positive emotional skills and attitudes that can lead children to higher achievement and success in life, better physical health, better relationships, more resilience against depression and anxiety, and even better conduct It is interesting to watch people's reactions when you tell them you are going to talk about happiness. The fact is, nobody wants to look like they take seriously something as frivolous as happiness. And yet, of course, there is nothing more seriously important as happiness and wellbeing (blurton fdc.com/articles/ 2013/12/4/theimportance-of-Well-being).

The findings of a number of studies indicated a negative correlation between smoking and individual well-being but this is not necessarily a causal relationship. For example, while it is reasonable to think that work stress and frustration may make people more inclined to smoke, it is equally attributed to think that smoking may increase feelings of frustration, irritation, and unhappiness (Lang, et al., 2007). Barbarin \& Richter, (2001); Ensink Robertson, Zissis, \& Leger, (1997) found that, Young people, in particular, are exposed to numerous environmental stressors within their communities, many of which have detrimental effects on their health and psychological well-being. Shafey et al., (2009) conducted study and reported Smoking-related mortality that occurs mostly in adulthood, smoking is initiated during adolescence, and the addictive nature of the habit makes quitting extremely difficult. Low well-being, specifically in the form of depression (or depressive symptoms), low self-esteem, or poor general health, is related to smoking as well as to alcohol use (e.g., Fernander et al.,2006). Research have shown that daily smokers report lower levels of well-being (Jurges, 2004; Shahab and West, 2009; Veenhoven, 2008). Abuse of alcohol, tobacco, cannabis, or other psychoactive substances has been reported to contribute to increase in the incidence of some psychological problems (Kandel, D. B. et.al; 1997 and Olfson M; 2000). Adolescents that abuse substances have higher prevalence of psychosocial problems when compared with the general adolescent population (Stanley, Eneh, Essien; 2000). Smoking affects subjective wellbeing. Individuals who smoke are more likely to report lower satisfaction with many aspects of their lives, e.g., jobs, non-working activities, financial conditions, family life, friendships, residential area, health and physical conditions, and self-rated health than those who do not smoke (Oshio \& Kobayashi, 2009). Men who do not smoke have been found to have higher average levels of wellbeing than men who smoke (Chanfraeu, et al., 2013). Smokers tend to report elevated levels of anxiety, with and without controlling for other factors (Annual Population Survey, 2012). There is evidence of a causal link between smoking and wellbeing: quitting smoking tends to reduce anxiety, with the effect likely to be larger in those who have a psychiatric disorder or those who smoke to reduce stress (McDermott et al., 2013). Smoking has a strong association with poor mental health. A third of people with a mental health disorder were regular smokers compared with a fifth of the population as a whole (McManus, Meltzer and Campion, 2010). There are many factors associated with smoking, including: social class, employment status, income, smoking status of family and friends. A number of these factors are also associated with people's wellbeing levels, for example employment status (Twigg, Moon and Jones (2000).

A recent review 38 studies indicated an increased risk for back pain in smokers as compared to nonsmokers in the majority of studies (Goldberg et al. 2000). In general, compared with nonsmokers, smokers tend to incur more medical costs, to see physicians more often in the outpatient setting, and to be admitted to the hospital more often. Among patients admitted to the hospital, smokers have longer lengths of stay and incur 
greater expenses per admission than non-smokers. Less information is available concerning the use of medical services such as prescription drugs and emergency department visits, but increases for smokers compared with nonsmokers have also been observed with respect to these outcomes (Chetwynd and Rayner, 1986; Miller et al. 1999). Current smokers report lower functional status than nonsmokers, in physical and especially in mental domains (Steven, et al., 1999).

\section{Objectives}

- To determine the Well-being among Frequent Smokers in comparison to Casual Smokers.

- To determine the Well-being among Frequent Smokers in comparison to Non-Smokers.

- To determine the Well-being among Casual Smokers in comparison to Non-smokers.

- To determine the Well-being among Frequent, Casual and Non-Smokers by comparing them with each other, taking into consideration the different dimensions of Well-being (Physical, Mental, Social, Emotional and Spiritual).

\section{Research Questions}

Taking into consideration the objectives of the present study, the following Research Questions were formulated:

- Do Casual Smokers maintain better Well-being while compared with Frequent Smokers?

- Do Non-Smokers are able to maintain better Well-being as compared with Frequent Smokers?

- Do Non-Smokers show better well-being as compared with Casual Smokers?

- Do Frequent, Casual and Non-smokers differ, from each other on different dimensions of Well-being (Physical, Mental, Social, Emotional and Spiritual)?

\section{Sample}

\section{METHODOLOGY}

The sample of youth residing in the halls of residence of Aligarh Muslim University was selected to serve as subjects for this study. The purposive Sampling technique was used to select the participants. The total sample consisted of 150 participants with equal number of Frequent Smokers $(n=50)$, Casual Smokers $(n=50)$ and Non-Smokers $(n=50)$. At the initial step, the information was collected from secondary sources about Smokers and Non-Smokers from every hall of residence. The lists of Smokers and Non-Smokers were prepared. Their consent was received and they were told about the purpose of the study. Some information about participants' smoking behavior and its frequency was noted by asking them some questions verbally. On the basis of their responses, these participants were divided into three groups: Frequent Smokers, Casual Smokers, and Non Smokers. The participants' age ranged between 16 to 19 years.

\section{Well-Being Scale}

\section{TOOL}

The Well-being Scale developed by Jagsharanbir Singh and Dr. Asha Gupta, (2001) was used. It is a 5point scale containing 50 statements with five dimensions namely Physical Well-being, Mental Well-being, Social Well-being, Emotional Well-being and Spiritual Well-being. The scores of every dimension are summed up to get a composite score of Well-being. The scores of a subject can vary from 50 to 250 . There are 29 positive items 21 negative items and they are scored as per the instructions given in the manual.

The scale is reliable, Test-retest reliability $=(0.98)$ and Split half reliability $=(0.96)$. Content and Concurrent validity was established. Concurrent validity of the scale was determined by comparing it with the scores of Subjective Well-being Inventory by Sall and Nagpal (1992). Correlation between Subjective Well-being inventory and different dimensions of this scale were $-0.45,0.78,-0.90,0.28$ and 0.18 respectively. The total correlation was found to be 0.53 .

V.

PROCEDURE

The participants were administered on Well-being Scale developed by Jagsharanbir Singh and Dr. Asha Gupta, (2001). According to the instructions given in the manual, their Well-being scores were obtained. These scores were analyzed by the means of $t$ test.

\section{RESULTS}

The aim of the present Study was to assess and compare the Well-being among Frequent, Casual and Non-Smoker Adolescents. The Mean, $\mathrm{SD}, \mathrm{SE}_{\mathrm{D}}$ and t-value for Overall Well-being among Frequent, Casual and Non-Smoker Adolescentsare presented in the following Ta ble. 
Table -1**Significant at 0.01 level, *Significant at 0.05 level

The obtained result showed that the Frequent and Casual smokers differed significantly on their measure of overall Well-being. The Overall t-value was found to be $6.29 * *$ which is significant at 0.01 level. This indicates

\begin{tabular}{|c|c|c|c|c|}
\hline \multirow{2}{*}{ Groups } & \multicolumn{4}{|c|}{ Overall Well-being } \\
\hline & Mean & SD & $\mathbf{S E}_{\mathbf{D}}$ & t-value \\
\hline Frequent Smokers & 170.00 & 15.57 & \multirow{2}{*}{2.92} & \multirow{2}{*}{$6.29 * *$} \\
\hline Casual Smokers & 188.36 & 13.56 & & \\
\hline Frequent Smokers & 170.00 & 15.57 & \multirow{2}{*}{2.30} & \multirow{2}{*}{$14.78 * *$} \\
\hline Non-smokers & 204.00 & 4.83 & & \\
\hline Casual Smokers & 188.36 & 13.56 & \multirow{2}{*}{2.03} & \multirow{2}{*}{$7.70^{* *}$} \\
\hline Non-Smokers & 204.00 & 4.83 & & \\
\hline
\end{tabular}

that Casual Smokers were maintaining better Well-being as compared to Frequent Smokers.

When Frequent Smokers were compared with Non-Smokers, a significant difference of ' $t$ ' $=14.78^{* *}$ was found, which is significant at 0.01 level. This means that Non-Smokers were better in their Well-being as compared to Frequent Smokers.And finally, a significant difference was also found out between Casual and Non-Smokers on their measure of Well-being. The t-value was found to be $7.70 * *$ which is significant at 0.01 level. This indicates that Non-Smokers are better in terms of Well-being when compared with Casual Smokers.

To conclude we can say that Non-Smokers were found to show better Well-being followed by Casual Smokers where as the Frequent Smokers were least concerning to their Well-being.

The following tables represent the descriptive statistics for different dimensions of Well-being among Frequent, Casual and Non-Smokers.

Table 2- represents dimension-wise Well-being of Frequent, Casual, and Non-Smokers in terms of Mean, $\mathrm{SD}, \mathrm{SE}_{\mathrm{D}}$, and t-value.

\begin{tabular}{|c|c|c|c|c|c|}
\hline \multirow{2}{*}{ GROUPS } & \multirow{2}{*}{ DIMENSIONS } & \multicolumn{4}{|c|}{ DIMENSION-WISE WELL-BEING } \\
\hline & & Mean & SD & $\mathbf{S E}_{\mathbf{D}}$ & t-value \\
\hline $\begin{array}{l}\text { Frequent } \\
\text { Smokers }\end{array}$ & \multirow{2}{*}{ Physical } & 30.68 & 5.04 & \multirow{2}{*}{0.932} & \multirow{2}{*}{$4.05^{* *}$} \\
\hline $\begin{array}{l}\text { Casual } \\
\text { Smokers }\end{array}$ & & 34.46 & 4.25 & & \\
\hline $\begin{array}{l}\text { Frequent } \\
\text { Smokers }\end{array}$ & \multirow{2}{*}{ Physical } & 30.68 & 5.04 & \multirow{2}{*}{0.761} & \multirow{2}{*}{$11.69 * *$} \\
\hline $\begin{array}{l}\text { Non- } \\
\text { Smokers }\end{array}$ & & 39.58 & 1.85 & & \\
\hline $\begin{array}{l}\text { Casual } \\
\text { Smokers }\end{array}$ & \multirow{2}{*}{ Physical } & 34.46 & 4.25 & \multirow{2}{*}{0.656} & \multirow{2}{*}{$7.80 * *$} \\
\hline $\begin{array}{l}\text { Non- } \\
\text { Smokers }\end{array}$ & & 39.58 & 1.85 & & \\
\hline $\begin{array}{l}\text { Frequent } \\
\text { Smokers }\end{array}$ & \multirow{2}{*}{ Mental } & 32.84 & 4.77 & \multirow{2}{*}{0.88} & \multirow{2}{*}{$7.32 * *$} \\
\hline $\begin{array}{l}\text { Casual } \\
\text { Smokers }\end{array}$ & & 39.28 & 3.99 & & \\
\hline $\begin{array}{l}\text { Frequent } \\
\text { Smokers }\end{array}$ & \multirow{2}{*}{ Mental } & 32.84 & 4.77 & \multirow{2}{*}{0.72} & \multirow{2}{*}{$9.55 * *$} \\
\hline $\begin{array}{l}\text { Non- } \\
\text { Smokers }\end{array}$ & & 39.72 & 1.83 & & \\
\hline $\begin{array}{l}\text { Casual } \\
\text { Smokers }\end{array}$ & \multirow{2}{*}{ Mental } & 39.28 & 3.99 & \multirow{2}{*}{0.62} & \multirow{2}{*}{0.71} \\
\hline $\begin{array}{l}\text { Non- } \\
\text { Smokers }\end{array}$ & & 39.72 & 1.83 & & \\
\hline $\begin{array}{l}\text { Frequent } \\
\text { Smokers }\end{array}$ & \multirow{2}{*}{ Social } & 35.18 & 5.92 & \multirow{2}{*}{1.002} & \multirow{2}{*}{1.56} \\
\hline $\begin{array}{l}\text { Casual } \\
\text { Smokers }\end{array}$ & & 36.74 & 3.90 & & \\
\hline Frequent & Social & 35.18 & 5.92 & 0.88 & \\
\hline
\end{tabular}




\begin{tabular}{|l|c|c|c|c|c|}
\hline Smokers & & & & $4.23 * *$ \\
\cline { 3 - 4 } $\begin{array}{l}\text { Non- } \\
\text { Smokers }\end{array}$ & 38.90 & 1.97 & & \\
\cline { 1 - 1 } $\begin{array}{l}\text { Casual } \\
\text { Smokers }\end{array}$ & \multirow{2}{*}{$\begin{array}{l}\text { Son- } \\
\text { Smokers }\end{array}$} & 36.74 & 3.90 & \multirow{2}{*}{0.62} & \multirow{2}{*}{$3.48 * *$} \\
\cline { 1 - 1 } & & 38.90 & 1.97 & & \\
\hline
\end{tabular}

The significant differences were found between Frequent Smokers and Casual Smokers on their measure of different dimensions of Well-being i.e. Physical, Mental, Emotional and Spiritual. The t-values were found to be $4.05 * *, 7.32 * *, 2.18 *$ and $3.90 * *$ respectively. These values are significant at 0.01 and 0.05 levels. This indicates that the Casual Smokers show better Physical, Mental, Emotional and Spiritual Well-being as compared to Frequent Smokers.An insignificant difference was found on the Social dimension of Well-being, when Frequent Smokers were compared with Casual Smokers. The t-value was found to be 1.56 which is insignificant at 0.01 level. This indicates that there is no difference between Frequent and Casual Smokers in terms of their Social Well-being.

Table 3- represents dimension-wise Well-being of Frequent, Casual, and Non-Smokers in terms of Mean, $\mathrm{SD}, \mathrm{SE}_{\mathrm{D}}$, and $\mathrm{t}$-value.

\begin{tabular}{|c|c|c|c|c|c|}
\hline \multirow{2}{*}{ GROUPS } & \multirow{2}{*}{ DIMENSIONS } & \multicolumn{4}{|c|}{ DIMENSION-WISE WELL-BEING } \\
\hline & & Mean & SD & $\mathbf{S E}_{\mathbf{D}}$ & t-value \\
\hline $\begin{array}{l}\text { Frequent } \\
\text { Smokers }\end{array}$ & \multirow{2}{*}{ Emotional } & 33.42 & 6.00 & \multirow{2}{*}{0.984} & \multirow{2}{*}{$3.90 * *$} \\
\hline $\begin{array}{l}\text { Casual } \\
\text { Smokers } \\
\end{array}$ & & 37.26 & 3.53 & & \\
\hline $\begin{array}{l}\text { Frequent } \\
\text { Smokers }\end{array}$ & \multirow{2}{*}{ Emotional } & 33.42 & 6.00 & \multirow{2}{*}{0.927} & \multirow{2}{*}{$10.23 * *$} \\
\hline $\begin{array}{l}\text { Non- } \\
\text { Smokers }\end{array}$ & & 42.90 & 2.62 & & \\
\hline $\begin{array}{l}\text { Casual } \\
\text { Smokers }\end{array}$ & \multirow{2}{*}{ Emotional } & 37.26 & 3.53 & \multirow{2}{*}{0.624} & \multirow{2}{*}{$9.04 * *$} \\
\hline $\begin{array}{l}\text { Non- } \\
\text { Smokers }\end{array}$ & & 42.90 & 2.62 & & \\
\hline $\begin{array}{l}\text { Frequent } \\
\text { Smokers }\end{array}$ & \multirow{2}{*}{ Spiritual } & 37.88 & 6.99 & \multirow[b]{2}{*}{1.260} & \multirow{2}{*}{$2.18 *$} \\
\hline $\begin{array}{l}\text { Casual } \\
\text { Smokers }\end{array}$ & & 40.62 & 5.52 & & \\
\hline $\begin{array}{l}\text { Frequent } \\
\text { Smokers }\end{array}$ & \multirow{2}{*}{ Spiritual } & 37.88 & 6.99 & \multirow[b]{2}{*}{1.044} & \multirow[b]{2}{*}{$4.81 * *$} \\
\hline $\begin{array}{l}\text { Non- } \\
\text { Smokers }\end{array}$ & & 42.90 & 2.39 & & \\
\hline $\begin{array}{l}\text { Casual } \\
\text { Smokers }\end{array}$ & \multirow{2}{*}{ Spiritual } & 40.62 & 5.52 & \multirow{2}{*}{0.85} & \multirow{2}{*}{$2.68 * *$} \\
\hline $\begin{array}{l}\text { Non- } \\
\text { Smokers }\end{array}$ & & 42.90 & 2.39 & & \\
\hline
\end{tabular}

The significant differences were found between Frequent Smokers and Non-Smokers on their measure of different dimensions of Well-being i.e. Physical, Mental, Social, Emotional and Spiritual. The t-values were found to be $11.69^{* *}, 9.55^{* *}, 4.23^{* *}, 10.23^{* *}$ and $4.81^{* *}$ respectively, which are significant at 0.01 level. This indicates that the Non-Smokers were significantly better in terms of Physical Well-being, Mental Well-being, Social Well-being, Emotional Well-being and Spiritual Well-being as compared to Frequent Smokers.And finally, when Casual Smokers were compared with Non-Smokers on Physical, Social, Emotional and Spiritual dimensions of Well-being, here also significant differences were found. The t-values were $7.80^{* *}, 3.48^{* *}$, $9.04 * *$ and $2.68 * *$ respectively, which are significant at 0.01 level. It means that Non-Smokers were significantly better in terms of their Physical, Social, Emotional and Spiritual Well-being as compared to Casual 
Smokers. An insignificant difference was found on the Mental dimension of Well-being, when Casual Smokers were compared with Non-Smokers. The t-value was found to be 0.71 which is insignificant at 0.01 level. This means that Casual Smokers do not differ from Non-Smokers in terms of Mental Well-being.

\section{DISCUSSION OF RESULTS}

The present study was conducted on adolescents and such type of study is needed to understand their problems because adolescence is considered to be a critical stage of an Individual's life. The adolescents seek pleasure because their life is filled with fantasies. So, they may make the use of hook or crook practices to bring pleasure in their lives for living a happy life. People who live in fantasy, they may take any sort of step for the fulfillment of their wants and desires. As they give less weight age to what is good and what is bad. But this is the stage when an individual is to be guided to go on a right track. So many factors will come into way through their family, living environment, peer groups in the locality and in the school and also the electronic media.

The main focus of this study is on Well-being among Non-Smokers and Smokers both Frequent and Casual. Take an example, when parents smoke in front of their children, as the adolescence is the stage of learning by imitation, they develop temptation to learn to smoke because of their parental influence. They try to inculcate this habit in themselves by making their parents as models. While selecting sample for this study, some questions were asked verbally to the participants about smoking habits and about its initiation. The participants' responses were noted. Most of smokers started smoking because they were influenced by their friends. Some of them smoked just for the enjoyment and fun, while others thought that to smoke is to achieve the dignity, honor and show adulthood.From their explanation, it became clear that they think that after smoking they feel relaxed and free of tension, they are able to solve the difficult problems, they get full concentration over the things they are dealing with and they feel happy and energetic. But many of them remain in normal condition before and after smoking. They expressed that when they do not smoke, they feel restlessness, irritation and lack of concentration. Though there is no particular time of smoking for them. While they are in friend circle, they have more temptation and urge for smoking, after having meals, visiting some places, after waking up from sleep in the morning. Some of them were badly addicted to this bad habit, they feel urge to smoke from dawn to dusk without assessing nicotine consequences. At this stage, they have become totally nicotine dependent and this level is to be maintained, which is only possible by. adapting continuity in smoking behaviour.The reasons of smoking could be attributed to stress caused by frustration, depression and non-achievement of their goal of life. They might be depressed and stressful when they have conflicts with their friends, going through parental pressure regarding their academic achievement, living away from parents, seem to be major issues related to adolescents. These factors could lead them towards substance abuse like tobacco smoking. The first finding of this study was that Non-Smokers showed significantly higher overall Well-being followed by Casual Smokers and lower Well-being was found among Frequent smokers. This finding is supported by Chanfraeu, et al., (2013), they conducted a study and found that Men who do not smoke have been found to have higher average levels of wellbeing than men who smoke. Research has also shown that daily smokers report lower levels of well-being (Jurges, 2004; Shahab and West, 2009; Veenhoven, 2008).Casual smokers could be considered as occasional Smokers, they smoke on particular occasions, therefore they get less impact of smoking upon themselves as compared to Frequent smokers. That is why they fall under average category in terms of their overall Well-being.The second finding of the study was that Casual smokers were found to show better Physical, Mental, Emotional and Spiritual Well-being as compared to Frequent Smokers. No significant difference was found between them in terms of their Social Well-being. It is obvious that both groups are Smokers, The differences in terms of their levels of Well-being could be due to the reason that Frequent Smokers are adversely affected by tobacco consuming and Casual Smokers are less affected by smoking because they smoke once in a week or they smoke occasionally. These two groups of adolescents are maintaining almost equal levels of Social Well-being due to the fact that both groups of subjects live in the society, have friends and smoking hardly matters for them when they engage themselves in activities that are for the welfare of the society.

The third finding of the study was that Non-Smokers maintain higher levels of Physical, Mental, Social, Emotional and Spiritual Well-being as compared to Frequent Smokers. The overall Well-being consisted of Physical, Mental, Social, Emotional and Spiritual dimensions. This finding is supported by several studies: Oshio \& Kobayashi, (2009), found that Smoking affects subjective wellbeing. Individuals who smoke are more likely to report lower satisfaction with many aspects of their lives, e.g., jobs, non-working activities, financial conditions, family life, friendships, residential area, health and physical conditions, and self-rated health than those who do not smoke.

Smokers tend to report elevated levels of anxiety, with and without controlling for other factors (Annual Population Survey, 2012). 
McManus, Meltzer and Campion (2010) conducted a study and found that Smoking has a strong association with poor mental health. A third of people with a mental health disorder were found regular smokers as compared with a fifth of the population as a whole.

Recent review summarizing 38 studies showed an increased risk for back pain in smokers as compared with nonsmokers in most of the studies (Goldberg et al. 2000)

The last finding of this study was that Non-Smokers were maintaining better Physical, Social, Emotional and Spiritual Well-being as compared to Casual smokers. This finding is supported by earlier studies as mentioned above that Non-Smokers maintain good Well-being. No difference was found in terms of their Mental Well-being. Casual Smokers are hardly smokers, Non-Smokers could be considered as passive Smokers. Therefore the impact of smoking could be the same on both the groups of adolescents. This finding could also be supported by incorporating view points of some Casual Smokers, they feel normal in both the conditions viz; before and after smoking, they do not feel any kind of relaxation when they smoke, they also don't feel any kind of irritability if they do not smoke. Their Mental Well-being remains somewhat intact. Therefore they did not show the sign of disturbed mental Well-being as compared with Non-Smoker counterpart.

\section{REFERENCES}

[1] Andrews, F. M. \& Withey, S. B. (1976). Social indicators of well-being. New York: Plenum Press; 63106.

[2] Annual Population Survey (2012). Analysis of the Annual Population Survey (2011/12) undertaken internally by Cabinet Office.

[3] Barbarin, O. A. \& Richter, L. (2001). Economic status, community danger and Chanfraeu, J., Lloyd, C., Byron, C., Roberts, C., Craig, R., De Feo, D., McManus, S. (2013).

[4] Chanfraeu, J., Lloyd, C., Byron, C., Roberts, C., Craig, R., De Feo, D., and McManus, S. (2013). Predicting Wellbeing. Prepared by NatCen Social Research for the Department of Health http://www.natcen.ac.uk/media/205352/predictors-of-wellbeing.pdf

[5] Chetwynd, J., Rayner, T. (1986). Impact of smoking on health care resource use. New Zealand Medical Journal; 99(799):230-2.

[6] Diener, E. (2009). Assessing well-being: the collected works of Ed. Diener. New York: Springer;

[7] Diener, E., Scollon, C. N., and Lucas, R. E. (2009). The evolving concept of subjective well-being: the multifaceted nature of happiness. In: Diener (ed.) Assessing well-being: the collected works of Ed Diener. New York: Springer; 67-100.

[8] Diener, E., Seligman, M. E. (2004). Beyond money. Toward an economy of well-being. Psychological Science in the Public Interest ; 5(1):1-31.

[9] Diener, E., Suh, E., and Oishi, S. (1997). Recent findings on subjective well-being. Indian journal of Clinical-Psychology ; 24:25-41.

Veenhoven, R. (2008). Sociological theories of subjective well-being. In: Eid, M., Larsen, R.J (eds). The science of subjective well-being. New York: Guilford Press; 44-61.

[10] Dunn, H.L. High level wellness. Beatty, R.W. Ltd: Arlington; (1973). Fernander, A. F., Flisher, A. J., King, G., Noubary, F., Lombard, C., Price, M., et al. (2006).

[11] Frederickson, B. L., Levenson, R.W. (1998). Positive emotions speed recovery from the cardiovascular sequelae of negative emotions. Cognition and Emotion ;12:191-220.

[12] Frey, B. S., and Stutzer, A. (2002). Happiness and economics. Princeton, N.J.: Princeton University Press;

[13] Gender differences in depression and smoking among youth in Cape Town, South Africa. Ethnicity \& Disease, 16, 41e50.

[14] Goldberg, M. S., Scott, S. C., Mayo, N, E. (2000). A review of the association between cigarette smoking and the development of nonspecific back pain and related outcomes. Spine ; 25(8):995-1014.

[15] http://www.blurton-fdc.com/articles/2013/12/4/the-importance-of-wellbeing.

[16] International Agency for Research on Cancer (IARC) Tobacco smoke and involuntary smoking. Lyon: IARC; 2004. Monographs on the evaluation of the carcinogenic risks to humans.

[17] Jha, P., Ramasundarahettige, C., Landsman, V., Rostron, B., Thun, M., Anderson, R. N., Mc Afee,T., Peto, R. (2013). 21st Century Hazards of Smoking and Benefits of Cessation in the United States. New England Journal of Medicine ; 368:341-50 [accessed 2014 Apr 24].

[18] Jürges, H. (2004). "The Welfare Costs of Addiction," Schmollers Jahrbuch, vol. 124(3).

[19] Kandel, D. B., Johnson, J. G., Bird, H.R. and Canino, G. (1997). Pstchiatric disorders associated with substance use among children and adolescents: findings from the methods for the epidemiology of child and adolescent mental disorders (MECA) study. Journal of American Academy and Child Psychology 12, $121-132$ 
[20] Krebsforschungszentrum, D (dkfz) Passivrauchen - ein unterschätztes Gesundheitsrisiko. Heidelberg: dkfz; 2005.

[21] Lang, I., Gardener, E., Huppert, F.A., et al. (2007). Was John Reid right? Smoking, class, and pleasure: a population-based cohort study in England. Public Health; 121: 518-24.

[22] Lyubomirsky, S., King, L., Diener, E. (2005). The benefits of frequent positive affect: does happiness lead to success? Psychol Bull ; 131(6):803-855.

[23] Mc Dermott, M. S., Marteau, T., Hollands, G., Hankins, M., and Aveyard, P. (2013). Change in anxiety following successful and unsuccessful attempts at smoking cessation: cohort study. The British Journal of Psychiatry, 202, 62-67.

[24] Mc Manus, S., Meltzer, H., Campion, J. (2010). Cigarette smoking and mental health in England: data from the Adult Psychiatric Morbidity Survey 2007. NatCen Social Research.

[25] Olfson, M., Shea, S., and Feder, A. (2000). Prevalence of anxiety , depression and substance use disorders in an urban general medicine practice. Arch Fam Med, 9, 876-883.

[26] Oshio, T. and Kobayashi, M. (2009). The effect of Smoking on Individual Wellbeing. Availableat http://www.ier.hit-u.ac.jp/pie/stage2/Japanese/d_p/dp2009/dp453/text.pdf

[27] Predicting Wellbeing. Prepared by NatCen Social Research for the Department of Health http://www.natcen.ac.uk/media/205352/predictors-of-wellbeing.pdf

[28] Pressman, S. D.,. Cohen, S. (2005). Does positive affect influence health? Psychol Bull;131:925-971. Psychological problems among South African children. Childhood, 8, 115e133.

[29] Ryff, C. D., Keyes, C. L. M. (1995). The structure of psychological well-being revisited. Journal of Personality and Social Psychology; 69(4):719-727.

[30] Shafey, O., Eriksen, M., Ross, H., \& MacKay, J. (2009). The tobacco atlas (3rd ed.). Atlanta, GA: The American Cancer Society.

[31] Shahab, L. and West, R. (2009). "Do Ex-Smokers Report Feeling Happier Following Cessation? Evidence from a Cross-Sectional Survey," Oxford University Press, Society for Research on Nicotine and Tobacco.

[32] Stanley, P.C., Eneh, A.U., Essien, A. A. (2005). Pattern of Childhood disorders in Port Harcourt Niger Delta region of Nigeria (Jan 1999 - Dec 2002). Nig J. Med, 14, 83-87

[33] Tov, W., Diener, E. (2008). The well-being of nations: Linking together trust, cooperation, and democracy. In: Sullivan, B. A., Snyder, M., Sullivan, J. L. (Eds.) Cooperation: The psychology of effective human interaction. Malden, M.A.: Blackwell Publishing;:323-342.

[34] Twigg, L., Moon, G., \& Jones, K. (2000). Predicting small-area health-related behaviour: a comparison of smoking and drinking indicators. Social Science and Medicine, 50, 1109-1120.

[35] US Department of Health and Human Services (USDHHS) USDHHS, Centers for Disease Control and Prevention, National Center for Chronic Disease Prevention and Health Promotion, Office on Smoking and Health. Atlanta, Georgia: USDHHS; (2004). The health consequences of smoking: a report of the surgeon general.

[36] Veenhoven, R. (2008). "Healthy Happiness: Effect of Happiness on Physical Health and the Consequences for Preventive Health Care," Journal of Happiness Studies, vol. 9, pages 449-464.

[37] Woolf, S. H, MD, MPH., Rothemich, S. F, MD., Johnson, R. E, PhD., Marsland, D. W,MD. Is cigarette smoking associated with impaired physical and mental functional status? An office-based survey of primary care patients.American Journal of Preventive Medicine Volume 17, Issue 2, August 1999, Pages $134-137$

[38] World Health Organization (WHO) The world health report (2002)- Reducing risks, promoting healthy life. Geneva: World Health Organization; (2002).

[39] World Health Organization. WHO Report on the Global Tobacco Epidemic, 2011 Geneva: World Health Organization, 2011 [accessed 2014 Apr 24].

[40] **http://timesofindia.indiatimes.com/india/India-home-to-second-highest-number-of-women-smokersglobally/articleshow/28548597.cms 